\title{
Suplementação de Creatina e Metabolismo de Glicose: Efeitos Terapêuticos ou Adversos?
}

\author{
"Carta ao Editor" referente ao artigo: \\ "Resistência à insulina com suplementação de creatina em animais de \\ experimentação". Costallat et al., 2007; v.13, n.1.
}

\author{
Bruno Gualano \\ Guilherme Gianini Artioli' \\ Antonio Herbert Lancha Junior \\ 1. Escola de Educação Física e \\ Esporte - Universidade de São \\ Paulo. Laboratório de Nutrição \\ e Metabolismo Aplicados à \\ Atividade Motora. Departamento \\ de Biodinâmica do Movimento \\ Humano
}

\author{
Endereço para correspondência: \\ Av. Prof. Mello Moraes, 65. \\ CEP 05508-900 - São Paulo, SP \\ - Brasil \\ Tel.: (51 11) 3091-3096 \\ Fax: (51 11) 3091-3136 \\ E-mail: gualano@usp.br
}

Submetido em 03/12/2007

Aceito em 11/04/2008
A hipótese do trabalho "Resistência à insulina com suplementação de creatina em animais de experimentação"é embasada na premissa de que os efeitos da suplementação de creatina sobre o metabolismo de carboidratos são mediados pela hipersecreção de insulina, a qual seria modulada, além da glicose, por proteínas e aminoácidos. Entretanto, a creatina não é uma proteína (conforme afirmam os autores), tampouco um aminoácido, mas um composto guanidínico sintetizado a partir de aminoácidos. Estudos in vitro da década de 70 relatam que, de fato, compostos guanidínicos são capazes de estimular moderadamente a secreção de insulina ${ }^{(1,2)}$. Estudos em humanos, entretanto, têm refutado constantemente hiperinsulinemia em decorrência da suplementação de creatina, tanto em jejum ${ }^{(3,4)}$ quanto após uma carga de glicose ${ }^{(5)}$. Dessa forma, a literatura aponta, ao contrário do que afirmam os autores, que a melhora na captação de glicose observada em modelo animal e humano se deve primordialmente a outros mecanismos não dependentes da insulina, como, por exemplo, aumento na expressão de GLUT-4 ${ }^{(6)}$.

Partindo da hipótese inicial, os autores afirmam que o objetivo do trabalho foi investigar se os efeitos da creatina na "hipersecreção de insulina podem induzir também resistência à insulina". Surpreendentemente, não foi apresentado nenhum dado demonstrando a resposta da concentração de insulina frente à suplementação de creatina. Além disso, não foram sequer fornecidas informações precisas sobre a quantidade de creatina consumida na dieta, já que a mesma foi administrada em água, cuja ingestão não foi mensurada. Sabe-se, ainda, que a creatina não se dissolve adequadamente em água, o que representar outro viés para as conclusões dos autores. Portanto, não podemos desconsiderar a hipótese de que a estratégia de suplementação utilizada no estudo tenha sido ineficaz.

A verificação da segurança da creatina é essencial, uma vez que esse suplemento é um dos mais consumidos no mundo. Embora os autores atestem que "certamente" a creatina pode apresentar alguns riscos à saúde, os achados de estudos controlados em humanos indicam o contrário ${ }^{(7,8)}$. A ingestão de creatina varia de 1 a 2g/dia em indivíduos não-vegetarianos, podendo chegar a até 7g/dia em sujeitos que consomem grandes quantidades de carne. Interessantemente, esses valores são por vezes superiores àqueles obtidos através da suplementação e nenhum efeito adverso aparente tem sido verificado. Além disso, deve-se observar que a extrapolação dos dados obtidos em animais para humanos é particularmente inadequada em estudos com creatina. O elegante estudo de Tarnopolsky et al. ${ }^{(9)}$, por exemplo, demonstrou que a creatina pode induzir hepatite em camundongos, mas não em ratos, salientando as diferenças nas respostas a essa amina mesmo entre espécies próximas. Portanto, a suposição dos autores, baseada em seus achados, de que possa haver em humanos "resistência à insulina em resposta à hipersecreção da mesma" (lembrando que essa variável não foi avaliada), é exageradamente especulativa e sem suporte científico adequado.

Os efeitos benéficos da suplementação de creatina no acúmulo de glicogênio muscular, tolerância à glicose e concentração de GLUT-4 continuam sendo fortes estímulos ao desenvolvimento de estudos terapêuticos em pacientes com intolerância à glicose ou resistência à insulina.

\section{REFERÊNCIAS BIBLIOGRÁFICAS}

Alsever RN, Georg RH, Sussman KE. Stimulation of insulin secretion by guanidinoacetic acid and other guanidine derivatives. Endocrinology 1970;86:332-6.

2. Marco J, Calle C, Hedo JA, Villanueva ML. Glucagon-releasing activity of guanidine compounds in mouse pancreatic islets. FEBS Lett 1976;64:52-4.

3. Gualano B, Novaes RB, Artioli GG, Freire TO, Coelho DF, Scagliusi FB, et al. Effects of creatine supplementation on glucose tolerance and insulin sensitivity in sedentary healthy males undergoing aerobic training. Amino Acids 2008;34:245-50

4. van Loon LJ, Murphy R, Oosterlaar AM, Cameron-Smith $D$, Hargreaves M, Wagenmakers AJ, et al. Creatine supplementation increases glycogen storage but not GLUT-4 expression in human skeletal muscle. Clin Sci (Lond) 2004;106:99-106.

5. Newman JE, Hargreaves M, Garnham A, Snow RJ. Effect of creatine ingestion on glucose tolerance and insulin sensitivity in men. Med Sci Sports Exerc 2003;35:69-74.

6. Op't Eijnde B, Urso B, Richter EA, Greenhaff PL, Hespel P. Effect of oral creatine supplementation on human muscle GLUT4 protein content after immobilization. Diabetes 2001;50:18-23.

7. Gualano B, Novaes RB, Shimuzu HM, Artioli GG, Rogeri PS, Ugrinowitsch C, et al. Aerobic training improves renal function and decreases oxidative stress in healthy sedentary males, despite high-dose JASN 2006;203A", por "Gualano B, Ugrinowitsch C, Novaes RB, Artioli GG, Shimuzu HM, et al. Effects of creatine supplementation on renal function: a randomized, double-blind, placebo-controlled clinical trial. Eur J Appl Physiol 2008; 103:33-40.

8. Gualano B, Ugrinowitsch C, Seguro AC, A.H. LJ. A suplementação de creatina prejudica a função renal? Rev Bras Med Esporte (in press)." por "Gualano B, Ugrinowitsch C, Seguro AC, Lancha Junior AH. A suplementação de creatina prejudica a função renal? Rev Bras Med Esporte 2008; 14:68-73.

9. Tarnopolsky MA, Bourgeois JM, Snow R, Keys S, Roy BD, Kwiecien JM, et al. Histological assessment of intermediate- and long-term creatine monohydrate supplementation in mice and rats. Am J Physiol Regul Integr Comp Physiol 2003;285:R762-9. 